\title{
LOS RECURSOS HUMANOS \\ Y SU IMPORTANCIA PARA EL DESARROLLO SECTORIAL
}

\author{
Claudio Muñoz Pereira. \\ Director Ejecutivo \\ Red de Turismo Sur Austral \\ Valdivia, Chile
}

\section{LA DIVERSIDAD DE ACTORES EN EL SECTOR TURISMO}

El sector turismo es un sector amplio, variado, cuya definición se ve reducida al traslado de una persona de un lugar a otro, con cierto grado de estadía, definición que se excede en ciertos casos, como el de profesionales y comerciantes que realizan movimientos de su hogar con fines laborales o comerciales y no relacionados con el turismo, aún cuando hacen uso de servicios comunes (Alimentación, Alojamiento y Servicios de Transporte).

Sin embargo esta definición general es la única posible de sustentar, en virtud a que no existe una posible desagregación, cuando se examinan cifras de todos los indicadores, que no discriminan sobre los objetivos de los movimientos humanos.

Por lo anterior, se optó por considerar cuatro aspectos básicos que acercan a la comprensión del fenómeno y surgen de cuatro preguntas básicas que sustentan cualquier tipo de actividad turística.

\section{Ocupaciones que se desarrollan en el sector Turismo}

\begin{tabular}{|c|c|c|}
\hline Pregunta & Subsectores & Ocupaciones \\
\hline ¿Dónde Dormir? & Hotelería & $\begin{array}{l}>\text { Recepcionista } \\
>\text { Botones } \\
>\text { Mucamas }\end{array}$ \\
\hline ¿Dónde Comer? & Restauración & $\begin{array}{l}>\text { Trabajadores de cocina } \\
>\text { Garzón } \\
>\text { Barman } \\
>\text { Anfitrión }\end{array}$ \\
\hline ¿Cómo Trasladarse? & Transporte & $\begin{array}{l}\text { D Transportista Terrestre Interurbano } \\
\text { D Transportista Acuático } \\
>\text { Transportista Aéreo } \\
\text { > Transportista Terrestre Local }\end{array}$ \\
\hline ¿Cómo Informarse? & Agencias y guías & $\begin{array}{l}>\text { Agente de Viajes } \\
>\text { Guías de Turismo }\end{array}$ \\
\hline
\end{tabular}


Si se observa con detención el esquema, se podrá identificar un conjunto de ocupaciones, las que no siempre son exclusivas del sector turismo; otras que siendo del mismo sector pueden encontrarse desempeñando funciones en distintos subsectores. Es el caso de los transportistas, los que no son exclusivos del sector turismo pero que muchas veces se encuentran en el sector como actividad anexa a otra principal. Así mismo las actividades de restauración (propia de los restaurantes) es de gran importancia en el subsector de hotelería, especialmente si la empresa es pequeña, micro o familiar, en virtud a que las actividades de hospedaje incluyen servicios de alimentación y bebidas.

Se puede señalar que en Hotelería y Restaurante, es necesario reducir las ocupaciones a tres básicas: mucamas, trabajadores de cocina y garzones. Las tendencias internacionales en la NET (Nueva Era del Turismo) se orientan al autoservicio en los transportes de equipajes personales y sus traslados menores. En este aspecto la actividad es reemplazada por la informática (tránsito directo a la habitación, mediante tarjetas electrónicas). En el caso del recepcionista se observan números equivalentes entre hombres y mujeres y la actividad de anfitrión (Welcomer o Willkoinmer) prácticamente es desconocida en la región.

En términos tendenciales es posible observar en el Transporte Terrestre y Acuático fluvial y lacustre, la multifuncionalidad de los transportistas, los que muchas veces son conductores y guías de turismo, sin preparación para ello, pero con un acumulado importante de experiencias por tradición oral. Sin embargo, la tendencia es el crecimiento de los Guías de Turismo, ya que cada vez los turistas son más exigentes en sus requerimientos: uso del lenguaje (materno como extranjero), comprensión adecuada, manejo de la información (cultural y natural de la zona).

\section{LA MULTIFUNCIONALIDAD DE LOS RECURSOS HUMANOS}

Uno de los fenómenos interesantes es la tendencia a la multifuncionalidad de algunas actividades en el sector turismo.

En el subsector de Hotelería y Restaurantes se observa los siguientes casos recurrentes:

- Trabajadores de Cocina y Garzones (en cualquiera de sus versiones dependiendo de las características del establecimiento), La proliferación de lugares de restauración del tipo microempresa o empresa familiar, genera una fuerza de trabajo considerable que combina la preparación de los alimentos con el servicio a la mesas.

- Garzones y Barman: en la mayor parte de los restaurantes no existe un especialista en la preparación de tragos y bebidas, por lo general, son los propios garzones, y mas concretamente los varones (es escasa la presencia de barwornan en la región), los que realizan ambas actividades.

- En el rubro de Hotelería, lo más frecuente es que las mucamas (rol esencialmente femenino), realicen labores de garzones en dos dimensiones: servicios a la habitación y otra en 
establecimientos de movimiento reducido de pasajeros, por razón de uso complementario del tiempo.

- En el subsector de transportes, se observa un doble rol del transportista: chofer y anexo a ello es guía de turismo.

- Así mismo muchos guías de turismo, proceden de otras actividades principales (profesores, especialistas en ciencias sociales, estudiantes de carreras universitarias). Otro caso, son los guías de turismo aventura, con dominio en escalamiento, los que por lo general han desarrollado o desarrollan actividades en el Ejército o participan en clubes especializados de andinismo o escalamiento.

- En relación a los Agentes, es posible observar que la función inicial se relaciona con actividades de Administración, ya sea de Empresa o Financiera, Relaciones Públicas y otras.

Todo lo anterior, se señala con el único interés en relevar esta multifuncionalidad, pues es la manifestación más clara de la superación fordiana o taylorista de los modelos económicos tradicionales (formación para un puesto de trabajo).

La multifuncionalidad es concebida como la posibilidad de una persona de poner en juego diversas competencias, según el tipo de actividad laboral que se le ofrezca o que automáticamente inicie. La mayor cantidad de competencias, ejercidas con calidad, proporcionará mayor estabilidad laboral en las personas abriendo los campos ocupacionales. Ello permite el cambio constante que impone la flexibilidad laboral, en la medida de que se mantenga bajo un concepto de formación y capacitación continua. Este hecho es relevante a la hora de concebir los diseños curriculares para la formación del recurso humano en cualquier ámbito, ya que serán las unidades de competencias (perfiles ocupacionales o profesionales) que se identifique en el mercado laboral las que indicarán la pertinencia de los perfiles de egreso que ofrezcan los centros formadores y las readecuaciones necesarias para responder a un mercado laboral real y orientar a los egresados hacia fuentes concretas de ocupación laboral.

\section{LA CALIFICACIÓN DEL RECURSO HUMANO}

Para los cuatro años siguientes (al menos hasta el 2008) no será necesario incorporar nuevo personal en las diversas actividades del turismo, con lo existente, podría considerarse el mercado saturado, siempre que la diferencia entre temporada alta y baja logre estabilizar la diferencia y generar empleo permanente y no temporal. Esta conclusión apriorística, deber ser considerada con ciertos matices:

- Si el 30\% de la instalación no ocupada logra efectivamente entrar en la dinámica del crecimiento, es necesario contar con la fuerza de trabajo correspondiente, es decir, habría necesidad de aumentar los recursos humanos en esa misma proporción, los que en primer lugar, procederían de aquel $20 \%$ que disminuye en la temporada baja, es decir, sólo habría necesidad de un $10 \%$ en este periodo (2005 - 2008), unos 1500 puestos de trabajo estable. 
- La mayor cantidad de actividades en el sector corresponden a oficios, que requieren menor o mayor grado de desarrollo de competencias laborales, que a la luz de las definiciones del concepto de NET, necesitan agregar valor a su actividad.

- La multifuncionalidad adquiere un rol decisivo, con lo cual los recursos humanos amplían su campo laboral.

- Las exigencias del turista actual cada vez se agudizan, en tanto, la actividad debe considerar altos estándares de calidad en infraestructura y atención al cliente. Se requiere intensos procesos de calificación de recursos humanos que respondan a estos parámetros internacionales. Esta sugerencia responde plenamente a los fundamentos para la creación del sistema nacional de Certificación de Competencias Laborales, tarea que moviliza a todo el sistema educativo y a la fuerza de trabajo.

- Al examinar las ofertas de formación, sorprende la escasa oferta en el subsector hotelería, fenómeno que responde al mercado laboral, el que es atendido directamente por personal capacitado en la propia experiencia laboral, sin estudios formales ni sistemáticos. Curiosamente, la oferta se realiza en Valdivia y el resto sur de la Región no es atendida, sino por niveles superiores de formación (Centros de Formación Técnica e Institutos Profesionales). Para efectos educacionales, este hecho obliga a examinar los perfiles de egreso, planes y programas, tratando de establecer pertinencia entre procesos de formación y requerimientos de competencias laborales. Igualmente debe ser examinada en los niveles universitarios.

- El aumento del flujo de turistas extranjeros caracteriza la demanda, en términos de nuevos requerimientos de calificación de la fuerza de trabajo y competencias laborales transversales. La necesidad del dominio de una segunda lengua (generalmente inglés), si no una tercera, se constituye en requisito para desempeñar ciertas funciones y tareas en el sector.

\section{LA CAPACITACION DE RECURSO HUMANO EN EL SECTOR TURISMO}

En el año 2001 la fuerza laboral capacitada en la región correspondió al 16, 9\% del país. Durante el año 2005 el programa Chile Califica, en las líneas de Capacitación por Competencias Laborales, el SENCE contempla desarrollar cursos de capacitación en el sector de turismo receptivo en los perfiles de: chofer turístico, welcomer, guía turístico, barman y garzón. 